Agronomía Costarricense 37(1): 23-38. ISSN:0377-9424 / 2013

www.mag.go.cr/rev_agr/index.html www.cia.ucr.ac.cr

\title{
PRESENCIA DE Colletotrichum acutatum Y Colletotrichum gloeosporioides EN HELECHO HOJA DE CUERO, LIMÓN CRIOLLO, PAPAYA, CARAMBOLA Y MANGO EN COSTA RICA Y FLORIDA (ESTADOS UNIDOS) ${ }^{1}$
}

\author{
Marcia Barquero Quirós*, Natalia A. Peres ${ }^{* *}$, Luis Felipe Arauz ${ }^{2 / * * *}$ \\ Palabras clave: Antracnosis, Colletotrichum gloeosporioides, Colletotrichum acutatum, mango, \\ papaya, carambola, lima, helecho hoja de cuero. \\ Keywords: Anthracnose, Colletotrichum gloeosporioides, Colletotrichum acutatum, mango, papaya, \\ starfruit, lime, leatherleaf fern. \\ Recibido: 09/08/12 \\ Aceptado: 06/12/12
}

\section{RESUMEN}

La antracnosis es una enfermedad causada por varias especies del género Colletotrichum en diferentes hospederos. C. acutatum y C. gloeosporioides son especies morfológicamente similares, que pueden causar síntomas similares en el mismo hospedero. Se colectaron 220 aislamientos de Colletotrichum de muestras con síntomas típicos de antracnosis en helecho hoja de cuero (Rumohra adiantiformis), limón criollo (Citrus aurantifolia), carambola (Averrhoa carambola), papaya (Carica papaya) y mango (Mangifera indica) en Costa Rica y Florida, Estados Unidos. Los aislamientos se caracterizaron por morfología de colonia, sensibilidad al benomil, y PCR con los iniciadores específicos para $C$. acutatum y C. gloeosporioides CaInt2 y Cg/fInt1, respectivamente; también se analizó la morfología de las colonias de ambas especies. De los 85 aislamientos obtenidos de mango, todos los aislamientos de Florida fueron identificados como C. acutatum, mientras que todos los aislamientos de Costa Rica fueron C. gloeosporioides. De los 60 aislamientos de carambola, 3 provenientes de Costa Rica fueron C. acutatum (primer informe) y el resto fueron C. gloeosporioides. Todos los

1/ Parte de la tesis de maestría de la primera autora.

2/ Autor para correspondencia. Correo electrónico: felipe.arauz@ucr.ac.cr

* Departamento de Microbiología y Genética Molecular, Universidad de Salamanca, España.

\begin{abstract}
Presence of Colletotrichum acutatum and Colletotrichum gloeosporioides on leatherleaf fern, key lime, papaya, star fruit and mango in Costa Rica and Florida (United States). Anthracnose is a disease caused by several species of the genus Colletotrichum on different hosts. C. acutatum and C. gloeosporioides are 2 morphologically similar species that can cause similar disease symptoms on the same host. A total of 220 isolates of Colletotrichum species were collected from typical anthracnose lesions on leatherleaf fern (Rumohra adiantiformis), Key lime (Citrus aurantifolia), starfruit (Averrhoa carambola), papaya (Carica papaya) and mango (Mangifera indica) in Costa Rica and Florida. Isolates were characterized by colony morphology, benomyl sensitivity and PCR with specific primers for $C$. acutatum and $C$. gloeosporioides CaInt 2 and $\mathrm{Cg} / \mathrm{fInt} 1$, respectively. Of the 85 isolates obtained from mango, all 33 isolates from Florida were identified as $C$. acutatum, whereas all isolates from Costa Rica were $C$. gloeosporioides. Out of 60 isolates obtained from starfruit, 3 isolates from Costa Rica were

\footnotetext{
** Gulf Coast Research and Education Center, University of Florida, Wimauma, FL, USA.

*** Centro de Investigaciones en Protección de Cultivos, Universidad de Costa Rica, San José, Costa Rica.
} 
aislamientos de helecho hoja de cuero (25 aislamientos) y de limón criollo (25 aislamientos) se identificaron como $C$. acutatum. Los demás aislamientos de carambola y mango así como todos los aislamientos de papaya, se identificaron como C. gloeosporioides. No se encontró diferenciación de síntomas entre ambas especies sobre los hospederos donde se encontraron.

\section{INTRODUCCIÓN}

Colletotrichum acutatum J.H Simmonds es un patógeno que afecta a numerosos hospederos en climas tropicales, subtropicales y templados (Bernstein et ál. 1995). Es el agente causal de la antracnosis en varios cultivos y de la caída prematura del fruto (PFD) en cítricos (Agostini et ál. 1992). El uso de técnicas moleculares y los avances en estudios de taxonomía y epidemiología permitieron la identificación de $C$. acutatum como causante de antracnosis en varios casos en los que se consideraba a $C$. gloesosporioides como el agente causal (Freeman et ál. 2001).

Existen pocos estudios sobre la identificación a nivel de especie del agente causal de la antracnosis en Costa Rica; en frutales como papaya (Carica papaya), mango (Mangífera indica) y aguacate (Persea americana), la antracnosis poscosecha generalmente se ha relacionado a C. gloeosporioides como el agente causal de la enfermedad (Arauz 2000); sin embargo, nuevos informes en otras partes del mundo han identificado a $C$. acutatum asociado con la antracnosis en estos frutales, entre ellos en mango en Florida (Peres et ál. 2005, Rivera et ál. 2006).

Freeman et ál. (2001) y Sreenivasaprasad y Talhinhas (2005); encontraron diferencias entre $C$. acutatum y $C$. gloeosporioides mediante técnicas moleculares y criterios morfológicos. Las principales características morfológicas, altamente variables y subjetivas, utilizadas para
C. acutatum (first report) and the rest were C. gloosporioides. All isolates from leatherleaf fern (25 isolates) and Key lime (25 isolates) were identified as $C$. acutatum. All remaining isolates from startfruit and mango, as well as all isolates from papaya, were C. gloeosporioides. There was no symptom difference between both Colletotrichum species on those hosts were both species were found.

distinguir $C$. acutatum de C. gloeosporioides y otras especies de Colletotrichum, son la forma de los conidios, la baja tasa de crecimiento, el color de la colonia y la secreción de pigmentos rojos o rosados al medio de cultivo (aislamientos cromogénicos) (Lardner et ál. 1999).

Otro método utilizado para distinguir entre C. acutatum y $C$. gloeosporioides es la prueba de sensibilidad a benomil; Peres et ál. (2004) encontraron una inhibición de un $80 \%$ en el crecimiento de aislamientos de $C$. acutatum en cultivo in vitro con concentraciones de benomil de 1 $\mu \mathrm{g} \cdot \mathrm{ml}^{-1}$, mientras que a esta misma concentración el crecimiento de $C$. gloeosporioides se inhibió totalmente. Asimismo encontraron aislamientos de $C$. gloeosporioides resistentes a benomil que no presentaron inhibición en su crecimiento.

Las herramientas moleculares son efectivas para distinguir entre las especies $C$. acutatum y C. gloeosporioides. Sreenivasaprasad et ál. (1996), Adaskaveg y Hartin (1997) y Schiller et ál. (2006), utilizaron exitosamente iniciadores específicos para C. acutatum (CaInt1 o CaInt2) combinados con el iniciador universal ITS4 para la detección del patógeno.

Entre los pocos estudios relacionados con C. acutatum en Costa Rica, se identificó como C. acutatum al agente causal de la antracnosis en fresa y helecho hoja cuero (Schiller et ál. 2006) y de la caída prematura de los frutos en cítricos (Arce 2003), mediante la reacción en cadena de la polimerasa (PCR). 
El objetivo de este estudio fue identificar las especies de Colletotrichum causantes de antracnosis en papaya, mango, carambola, helecho hoja de cuero y limón criollo en Costa Rica y Florida (USA), mediante la prueba de sensibilidad a benomil y mediante PCR con iniciadores específicos.

\section{MATERIALES Y MÉTODOS}

\section{Muestreo de Colletotrichum spp., y mantenimiento de aislamientos}

Se colectaron muestras con síntomas de antracnosis en diferentes sitios y cultivos de
Costa Rica y Florida durante el 2006, 2007 y 2008 (Cuadro 1, Figura 1), se trasladaron al laboratorio en bolsas plásticas y se almacenaron a $4^{\circ} \mathrm{C}$. Al cabo de 24 o $48 \mathrm{~h}$ se realizaron los aislamientos y se tomaron fotografías de las lesiones.

Se realizaron aislamientos en medio Papa Dextrosa Agar (PDA) acidificado, a partir de la zona de avance de la lesión o directamente de raspados de acérvulos. Los aislamientos se mantuvieron en crecimiento con oscuridad a $24^{\circ} \mathrm{C}$, durante mínimo una semana; se realizaron cultivos monospóricos de cada aislamiento. 


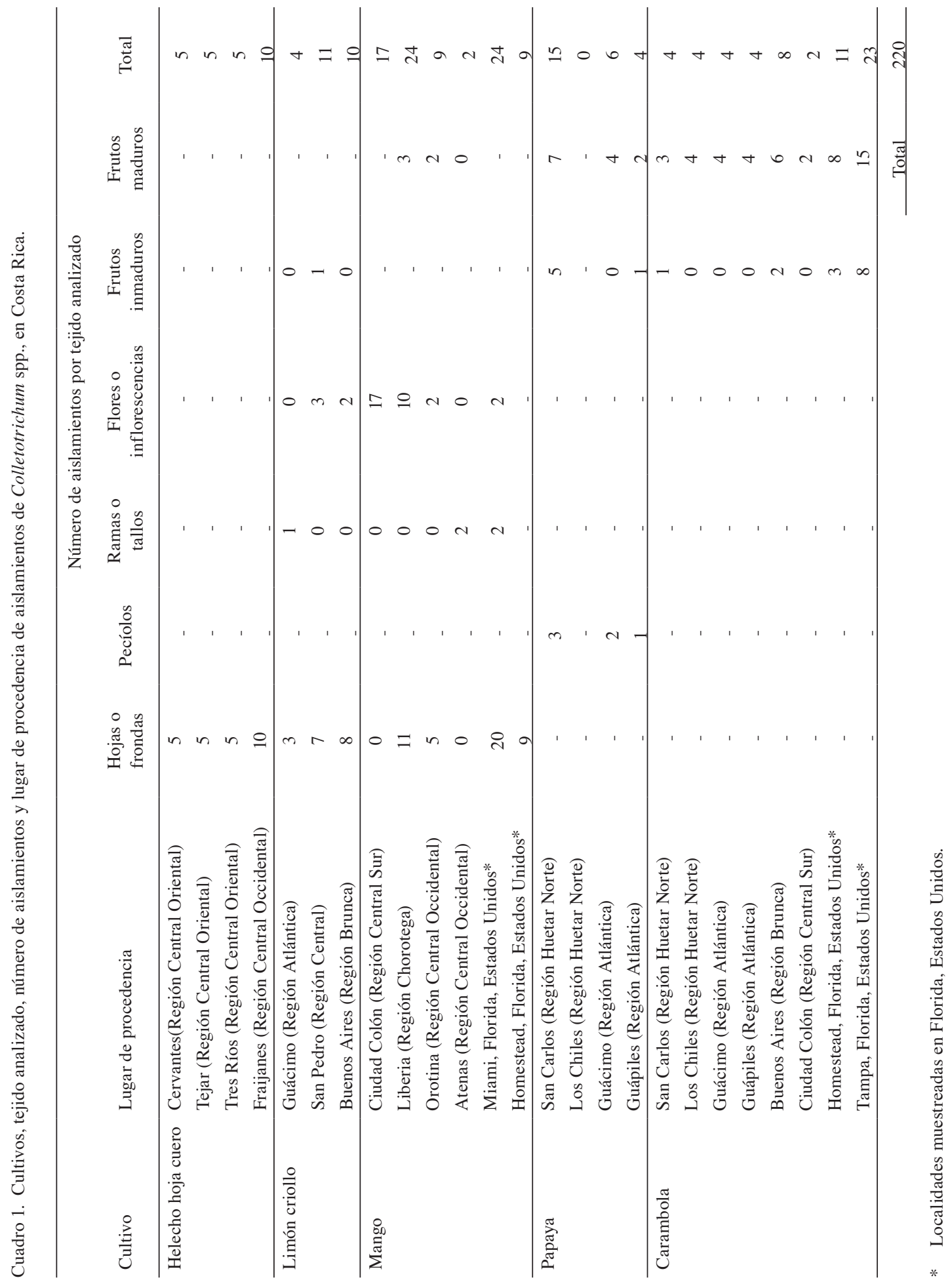




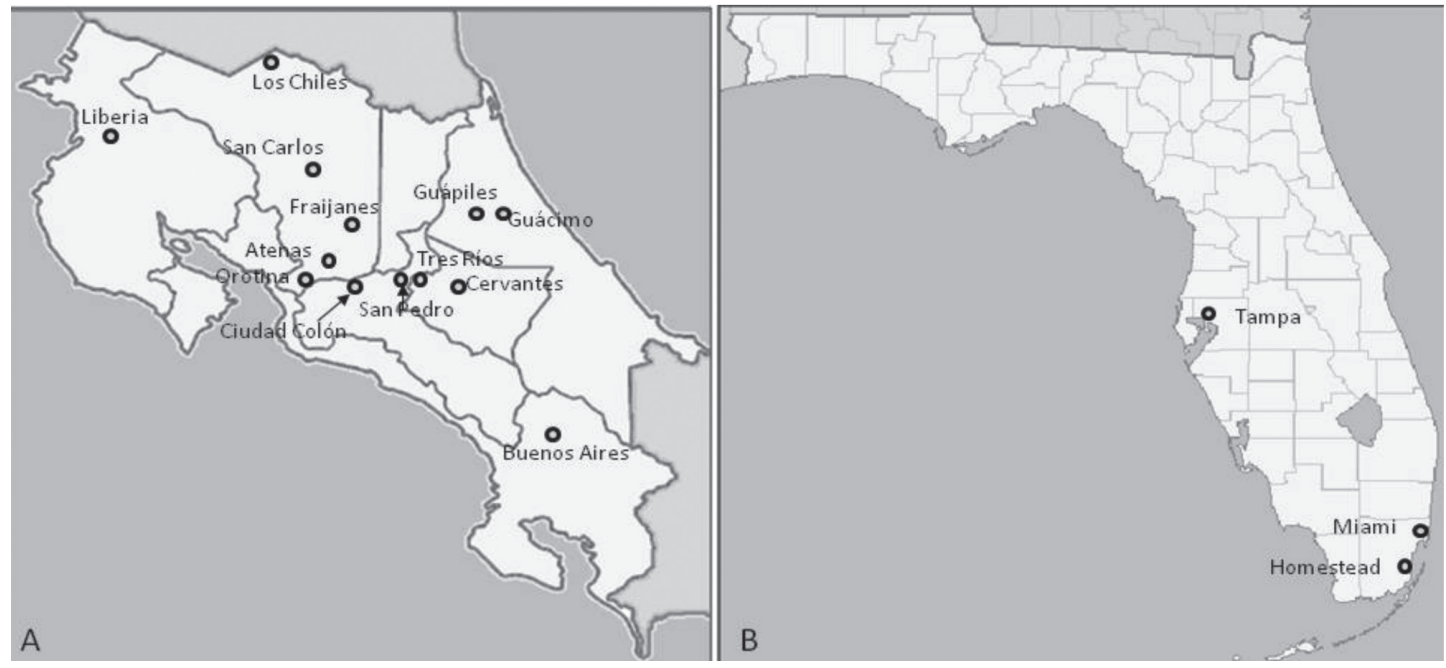

Fig. 1. Sitios muestreados para antracnosis en helecho hoja de cuero (Rumohra adiantiformis), limón criollo (Citrus aurantifolia), mango (Mangifera indica), papaya (Carica papaya) y carambola (Averrhoa carambola) en (A) Costa Rica y (B) Florida, Estados Unidos.

\section{Prueba de sensibilidad a benomil}

Del borde de la colonia de cada aislamiento monospórico se tomaron 4 cuadrados de $3 \mathrm{~mm}$ de lado; se transfirieron 2 secciones a platos Petri con PDA y los otros 2 a PDA con benomil ( $1 \mu \mathrm{g}$. $\left.\mathrm{ml}^{-1}\right)$. Se realizaron 3 repeticiones y se incubaron durante una semana en oscuridad a $24^{\circ} \mathrm{C}$. Se realizaron comparaciones visuales del crecimiento de la colonia para determinar la sensibilidad al benomil, según el crecimiento:

A: Tasa de crecimiento menor en medio PDA con benomil que en medio PDA

B: Tasa de crecimiento igual en medio PDA con benomil y en medio PDA

C: Ausencia de crecimiento en medio PDA con benomil

El caso A correspondería a $C$. acutatum sensible al benomil, el B a C. gloeosporioides resistente a benomil, y el $\mathrm{C}$ a $C$. gloeosporioides sensible a benomil.

\section{Identificación por PCR con iniciadores específicos}

Se tomó un trozo micelio de la zona de crecimiento de cada aislamiento monospórico y se puso a crecer en $50 \mathrm{ml}$ de medio líquido Emmerson (4 g de extracto de levadura, $15 \mathrm{~g}$ de almidón soluble, $1 \mathrm{~g}$ de $\mathrm{K}_{2} \mathrm{HPO}_{4}$ y $0,5 \mathrm{~g}$ de $\mathrm{MgSO}_{4}$ por litro) durante 3 días en agitación a 170 rpm y luego se filtró al vacío con papel Whatman número 3. Se dejó durante toda la noche en un evaporador centrifugal. El ADN de los hongos se extrajo por medio del método CTAB (Xiao et ál. 2004), que consiste en la utilización de un tampón de extracción a base de Hexadeciltrinmetilbromuro de amonio (CTAB).

Para la detección de $C$. acutatum se utilizó el iniciador específico CaInt2 (5'-GGGGAAGCCTCTCGCGG-3') (Sreenivasaprasad et ál. 1996) junto con el iniciador universal ITS4 (5'-TCCTCCGCTTATTGATATGC-3') (White et ál. 1990). Para la detección de C. gloeosporioides se utilizó el iniciador específico $\mathrm{Cg}$ / fInt1 (5'-GACCCTCCCGGCCTCCCGCC-3') 
(Ureña-Padilla et ál. 2001) junto con el iniciador universal ITS4.

La amplificación se llevó a cabo en un volumen de reacción de $20 \mu \mathrm{l}$ con una concentración final de: $1 \mathrm{X}$ de Buffer de PCR Perkin Elmer, 1,5 mM de $\mathrm{MgCl}_{2}, 0,2 \mathrm{mM}$ dNTP's, $1 \mu \mathrm{M}$ CaInt2 o Cg/fInt1, $1 \mu \mathrm{M}$ ITS4 y $1 \mathrm{U}$ de Taq polimerasa (Applied Biosystems, Foster City, USA). En la reacción de PCR de $C$. acutatum además se añadió glicerol al 6\%.

Para la PCR de C. gloeosporioides usó el siguiente programa: $94^{\circ} \mathrm{C}$ por $5 \mathrm{~min}$ para la desnaturalización del $\mathrm{ADN}$ y 26 ciclos de $94^{\circ} \mathrm{C}$ por $1 \mathrm{~min}, 60^{\circ} \mathrm{C}$ por $2 \mathrm{~min}$ y $72^{\circ} \mathrm{C}$ por $2 \mathrm{~min}$; luego $72^{\circ} \mathrm{C}$ por 10 min y finalmente $4^{\circ} \mathrm{C}$. Los parámetros de temperatura para la PCR en el caso de $C$. acutatum fueron los mismos que para C. gloeosporioides pero con 32 ciclos (MacKenzie S.J. 2008. Comunicación personal). Los productos de PCR se corrieron en un gel de agarosa al 1,5\% con bromuro de etidio incorporado y se visualizaron con luz ultravioleta (UV). Se utilizaron como positivos aislamientos de la colección del laboratorio de fitopatología de la Universidad de Costa Rica de fresa y helecho hoja de cuero identificados previamente como C. gloeosporioides y C. acutatum respectivamente.

\section{Medición de colonias y conidios de $C$. acutatum}

Se midió el diámetro de 5 colonias y la longitud de 10 conidios escogidos al azar de 3 aislamientos de mango (Mn10, Mn38 y Mn43) y 2 aislamientos de carambola (Car1 y Car2) identificados todos como C. acutatum. Además, para fines comparativos, se midió el diámetro de colonias de $C$. gloeosporioides de carambola y mango.

\section{RESULTADOS}

\section{Muestreo de Colletotrichum spp., y caracterización de colonias}

Se obtuvieron aislamientos a partir de lesiones de antracnosis de diferentes tejidos de helecho hoja de cuero, limón criollo, mango, papaya y carambola (Cuadro 1). En limón criollo la lesión consistió en la necrosis de las hojas con producción de acérvulos sobre lesiones viejas (Figura 2A y 2B). En limón criollo también se observaron lesiones y acérvulos en inflorescencias y frutos. En carambola se definen claramente 2 tipos de lesiones en fruto: una mancha necrótica irregular y una necrosis en los vértices de la fruta; sobre ambas lesiones hay producción de acérvulos (Figura 2C y 2D). En helecho hoja de cuero la lesión consistió en la necrosis de las frondas de la planta (Figura 2E y 2F).

En mango, las hojas presentaron lesiones irregulares de gran tamaño en los márgenes de las hojas, zonas necróticas en las venas, o pequeñas lesiones necróticas que con el tiempo se convirtieron en perforaciones. También se observó necrosis en flores y en el tallo de las panículas 


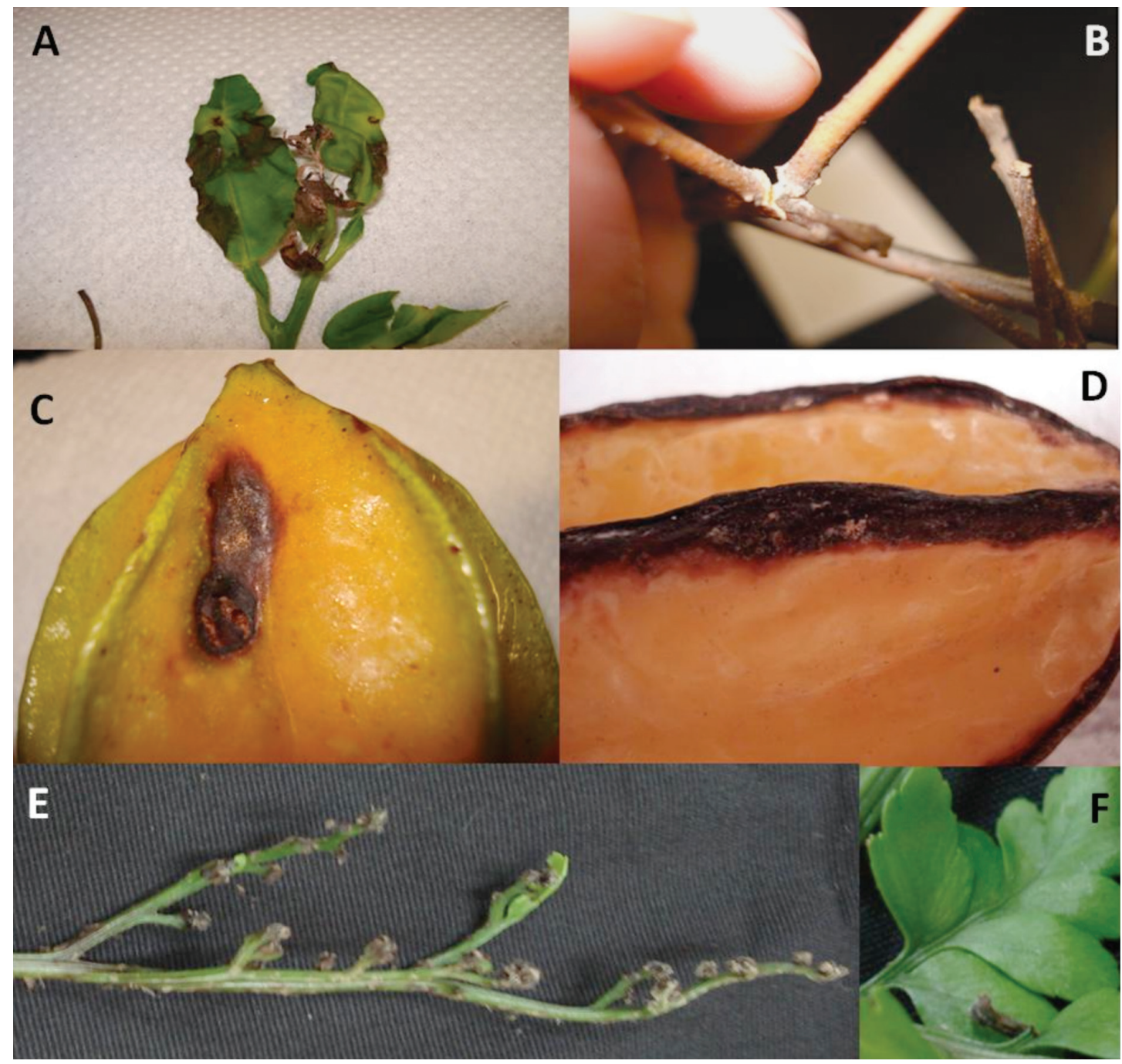

Fig. 2. Síntomas típicos de antracnosis causados por Colletotrichum spp., en diferentes cultivos. (A, B) Hojas y ramas secas de limón criollo. (C, D) Carambola. (E, F) Helecho hoja de cuero.

(Figura 3A-H). En papaya, se encontraron lesiones redondeadas, hundidas, con producción de acérvulos en fruto maduro e inmaduro y lesiones sin hundimientos y de color marrón llamadas mancha chocolate. En los pecíolos de las hojas se observaron lesiones pequeñas ovaladas con halos claros (Figura 4A-D).
En total se obtuvieron 220 aislamientos identificados por características morfológicas como Colletotrichum sp. Además se recuperaron 30 aislamientos correspondientes a otros hongos como Fusarium spp. Pestalotia sp., y Macrophomina sp., provenientes de mango, papaya $\mathrm{y}$ carambola. 


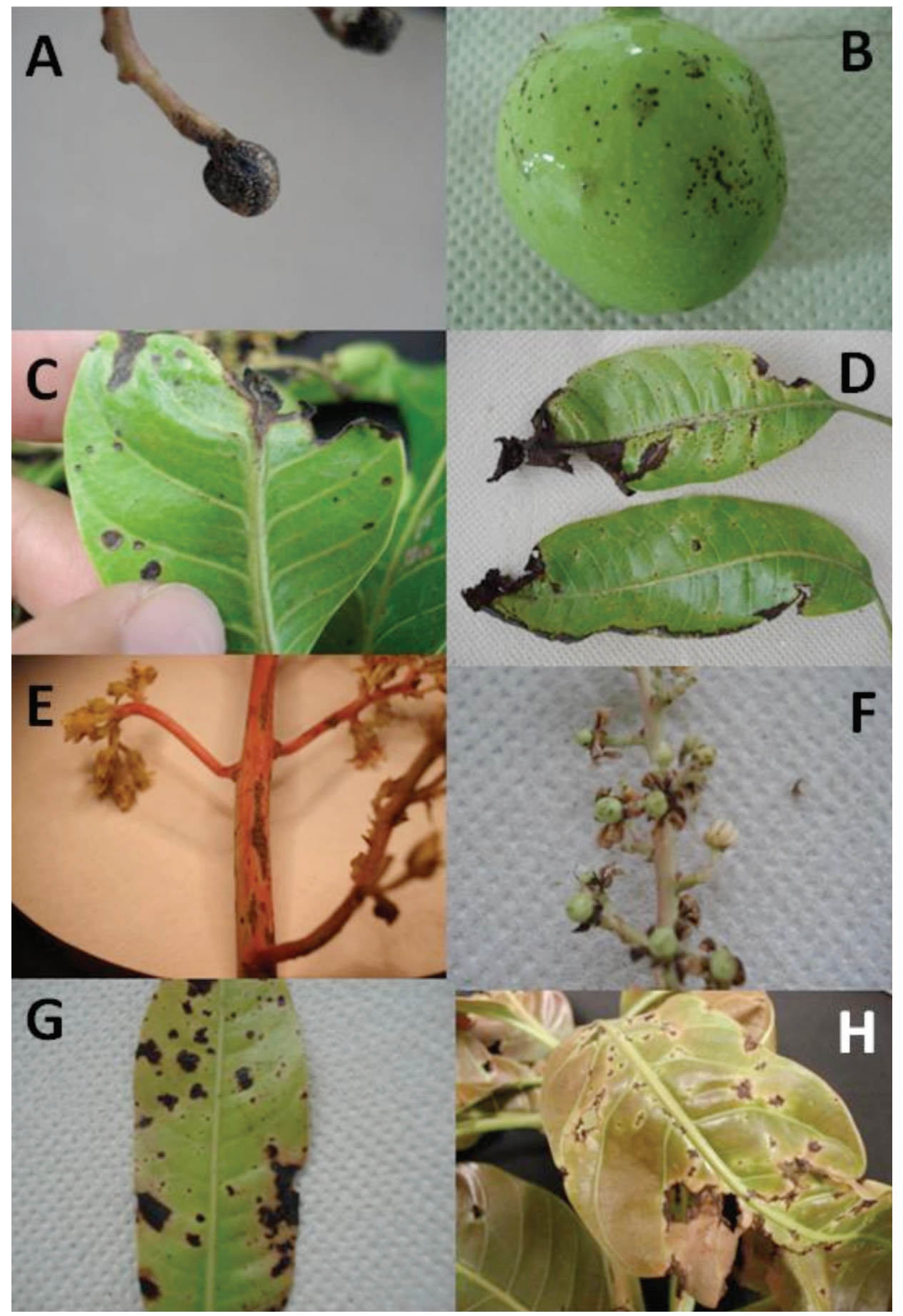

Fig. 3. Síntomas típicos de antracnosis causados por Colletotrichum spp., en mango. (A, B) Fruto momificado y fruto inmaduro. (C, D) Hojas maduras. (E, F) Panículas y flores. (G, H) Hojas jóvenes. 


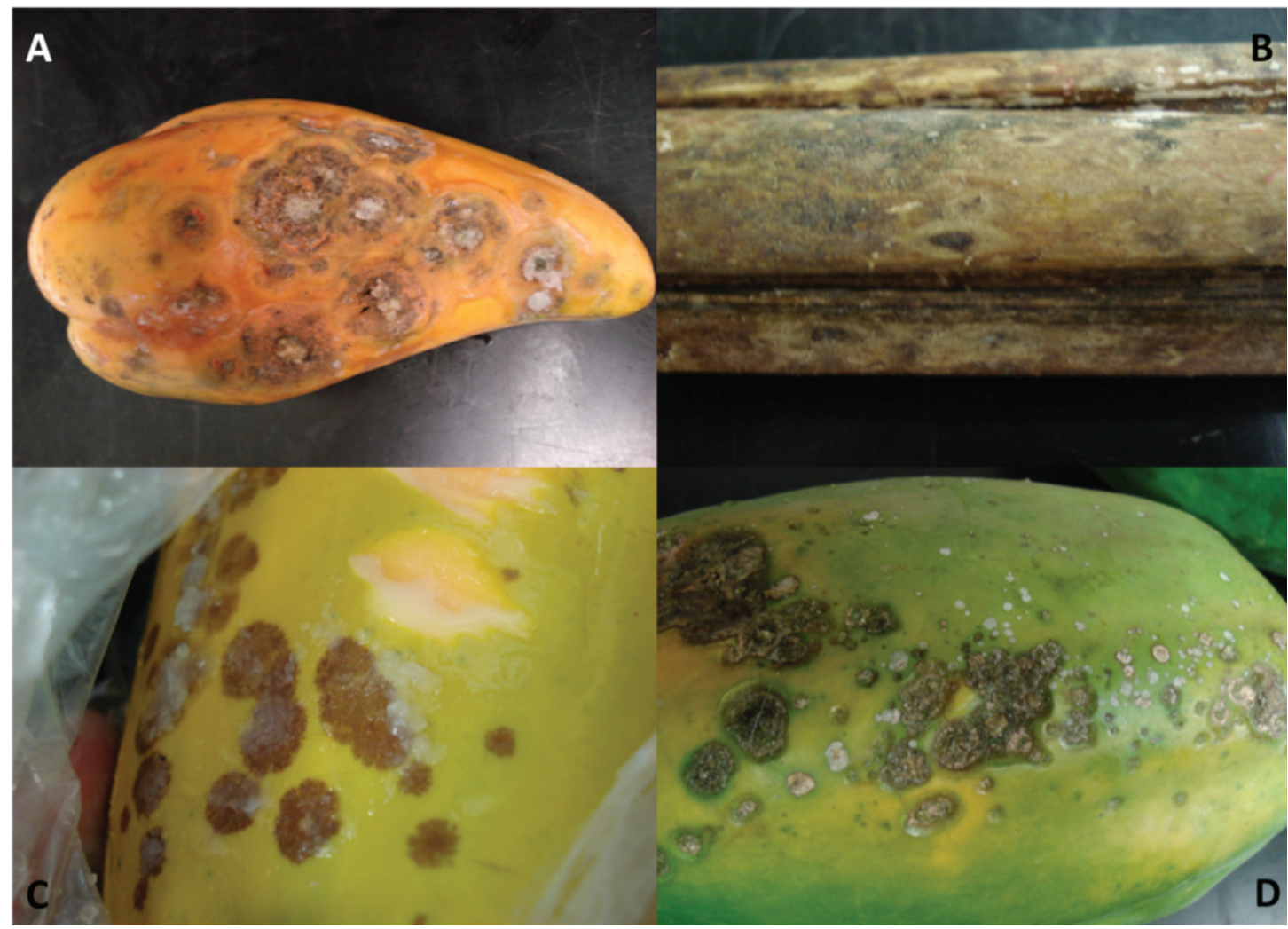

Fig. 4. Síntomas típicos de antracnosis causados por Colletotrichum spp., en papaya. (A) Fruto maduro. (B) Pecíolo. (C) Mancha chocolate. (D) Fruto inmaduro.

La morfología de las colonias fue variable (Figura 5) y esta variabilidad dependió de cada hospedero. Las colonias provenientes de mango fueron altamente variables en su morfología (Figura 5A-F). Se obtuvieron colonias blancas y grises con masas naranjas de conidios distribuidas en toda la colonia o en el centro de la misma. Algunos aislamientos presentaron anillos concéntricos y puntos negros (estroma o micelio compactado) distribuidos por toda la colonia (Figura 5D). Algunos aislamientos grises presentaron micelio blanco en su perímetro (Figura 5F). Los aislamientos de C. acutatum de mango, provenientes de Florida, se caracterizaron por la distribución de acérvulos naranja intenso, casi rojo, en toda la colonia (Figura 5I). En carambola y papaya, se obtuvieron colonias blancas y grises con masas naranjas de conidios distribuidas y en el centro de la colonia (Figura $5 \mathrm{G}$ y $\mathrm{H}$ ); de ambos hospederos se recuperaron colonias blancas con centro anaranjado. También se presentaron colonias grises con micelio blanco en el perímetro. En las colonias provenientes de papaya, se observaron anillos concéntricos. Los aislamientos provenientes de helecho hoja de cuero (Figura 5J) fueron grises con masas de conidios naranja (acérvulos) y estroma o micelio compacto. Se obtuvieron 2 tipos de colonias de limón criollo: blancas con el centro naranja y grises con algunas masas de conidios naranja (Figura 5K). Algunas colonias similares a las obtenidas de limón criollo, blancas con centro anaranjado, se recuperaron de carambola (Figura 5L) y de papaya. 


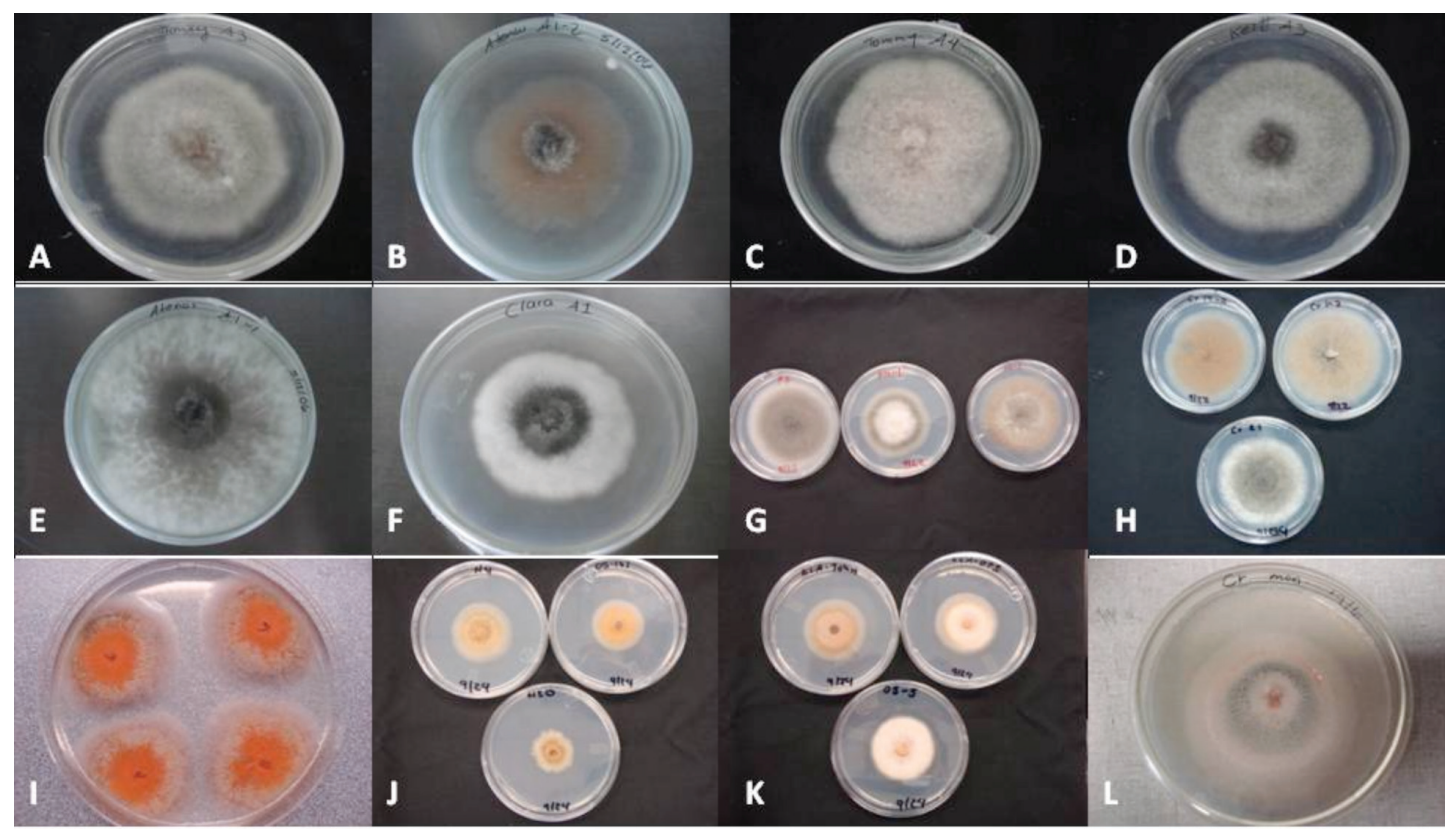

Fig. 5. Morfología de colonias de Colletotrichum spp. (A-F) C. gloeosporioides aislado de mango. (G) C. gloeosporioides de papaya. (H) C. gloeosporioides de carambola. (I) C. acutatum de mango. (J) C. acutatum de helecho hoja de cuero. (K) C. acutatum de limón criollo. (L) C. acutatum de carambola.

\section{Identificación por PCR con iniciadores específicos y prueba de sensibilidad a benomil}

Todos los aislamientos provenientes de helecho hoja de cuero (25), y de limón criollo (25), 3 provenientes de carambola y 33 aislamientos de mango de Florida resultaron positivos en la amplificación por PCR con el iniciador específico para $C$. acutatum CaInt2. El tamaño de la banda obtenida fue de 490 pb (Figura 6). Estos aislamientos resultaron negativos cuando se realizó la PCR con el iniciador específico para C. gloeosporioides $\mathrm{Cg} / \mathrm{fInt} 1$. El resto de aislamientos amplificaron en la PCR con el iniciador específico $\mathrm{Cg} / \mathrm{fInt}$, específico para $C$. gloeosporioides, con el que se obtuvo una banda de $450 \mathrm{pb}$ (Figura 6) y no amplificaron con el primer CaInt2.

La mayoría de los aislamientos fueron sensibles a benomil; 95 aislamientos (43\%) no presentaron crecimiento en el medio de PDA con benomil; 19 aislamientos $(8,6 \%)$ tuvieron una tasa de crecimiento igual en ambos medios y 106 aislamientos (48\%) presentaron menor crecimiento en medio PDA con benomil que en PDA solo. (Cuadro 2).

Los 25 aislamientos de helecho hoja de cuero fueron identificados como C. acutatum en la prueba de sensibilidad a benomil y en la PCR. En limón criollo, sucedió lo mismo con 22 aislamientos, mientras que otros 3 según la prueba de benomil correspondían a $C$. gloeosporioides y según la PCR se trataba de C. acutatum (Cuadro 2).

En mango, los 33 aislamientos identificados como $C$. acutatum por la PCR, fueron identificados como C.acutatum también en la prueba de sensibilidad a benomil, 38 aislamientos fueron identificados como C. gloeosporioides en ambas pruebas y 5 aislamientos como C. gloeosporioides resistentes a benomil. Por otro lado, 9 aislamientos de mango identificados como $C$. acutatum mediante la prueba de benomil, resultaron ser C. gloeosporioides con la PCR con iniciadores específicos. 


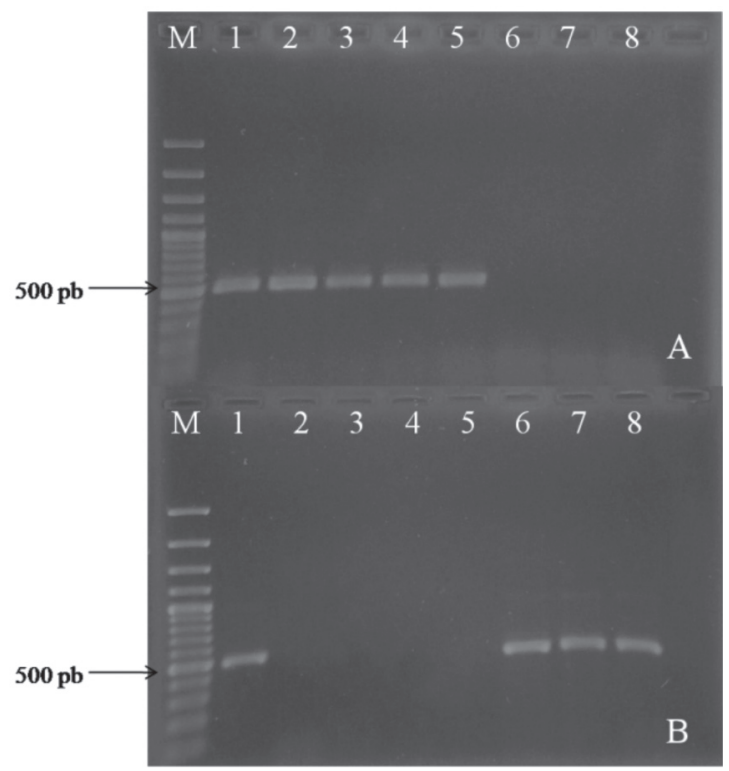

Fig. 6. (A) Fragmentos amplificados con los iniciadores CaInt 2 x ITS4 para C. acutatum. (B) Fragmentos amplificados usando los iniciadores Cg/fInt1 x ITS4 para C. gloeosporioides. (1) Controles positivos para cada especie. Aislamientos provenientes de (2) helecho hoja de cuero, (3) limón criollo, (4) mango/C. acutatum, (5) carambola/C. acutatum, (6) mango/C. gloeosporioides, (7) carambola/C. gloeosporioides, (8) papaya.

Cuadro 2. Sensibilidad a benomil de aislamientos según hospedero.

\begin{tabular}{|c|c|c|c|c|c|c|}
\hline \multirow{3}{*}{ Hospedero } & \multicolumn{6}{|c|}{ Número de aislamientos } \\
\hline & \multicolumn{2}{|c|}{ A } & \multicolumn{2}{|c|}{ B } & \multicolumn{2}{|c|}{$\mathrm{C}$} \\
\hline & C. $a^{*}$ & C.g** & C.a & C.g & C.a & C.g \\
\hline Helecho hoja cuero & 25 & 0 & 0 & 0 & 0 & 0 \\
\hline Limón criollo & 22 & 0 & 3 & 0 & 0 & 0 \\
\hline Mango & 33 & 9 & 0 & 5 & 0 & 38 \\
\hline Papaya & 0 & 14 & 0 & 8 & 0 & 3 \\
\hline Carambola & 3 & 0 & 0 & 3 & 0 & 54 \\
\hline Total & \multicolumn{2}{|c|}{106} & \multicolumn{2}{|c|}{19} & \multicolumn{2}{|c|}{95} \\
\hline
\end{tabular}

A: Tasa de crecimiento menor en medio PDA + benomil que en PDA (C. acutatum sensible a benomil).

B: Tasa de crecimiento igual en medio PDA con benomil y en medio PDA. (C. gloeosporioides resistente a benomil).

C: Ausencia de crecimiento en medio PDA con benomil. (C. gloeosporioides sensible a benomil).

*C. acutatum según resultados de la PCR.

** C. gloeosporioides según resultados de la PCR. 
En el caso de papaya, los 14 aislamientos identificados como $C$. acutatum mediante la prueba de sensibilidad a benomil fueron identificados como C. gloeosporioides con la PCR. También se identificaron 11 aislamientos más como $C$. gloeosporioides con esta prueba, de los cuales 8 correspondieron a aislamientos resistentes a benomil (Cuadro 2).

Por último, en carambola hubo concordancia con los resultados obtenidos en la prueba de sensibilidad a benomil y en la PCR con iniciadores específicos (Cuadro 2).

\section{Medición de colonias y conidios de $C$. acutatum}

Los conidios de $C$. acutatum de mango fueron más grandes que los de carambola (Cuadro 3), mientras que el diámetro de la colonias procedentes carambola fue mayor que en las procedentes de mango. Las colonias de C. $a c u$ tatum presentaron una tasa de crecimiento menor que las colonias de C. gloeosporioides. Los conidios de C. acutatum provenientes de mango y carambola presentaron extremos fusiformes, al contrario de los conidios procedentes de $C$. gloeosporioides (Figura 7).

Cuadro 3. Longitud de conidios y diámetro de colonias de aislamientos de C. acutatum y C. gloeosporioides de carambola y mango.

\begin{tabular}{lcc}
\hline Aislamiento & Longitud de conidio $(\mu \mathrm{m})^{*}$ & Diámetro de colonia $(\mathrm{cm}) * *$ \\
\hline Carambola (Car 1) & $6,3 \pm 0,67$ & $6,10 \pm 0,26$ \\
Carambola (Car 2) & $6,4 \pm 1,35$ & $5,98 \pm 0,15$ \\
Carambola (C. gloeosporioides) & No se midió & $6,96 \pm 0,17$ \\
Mango (10) & $8,8 \pm 0,92$ & $4,68 \pm 0,22$ \\
Mango (38) & $8,6 \pm 0,84$ & $4,44 \pm 0,23$ \\
Mango (43) & $8,7 \pm 1,33$ & $4,62 \pm 0,28$ \\
Mango (C. gloeosporioides) & No se midió & $6,08 \pm 0,11$ \\
\hline
\end{tabular}

*Promedio de 10 conidios por aislamiento \pm Desviación estándar.

**Promedio de 5 colonias por aislamiento \pm Desviación estándar.

Edad de los cultivos: 8 días. 


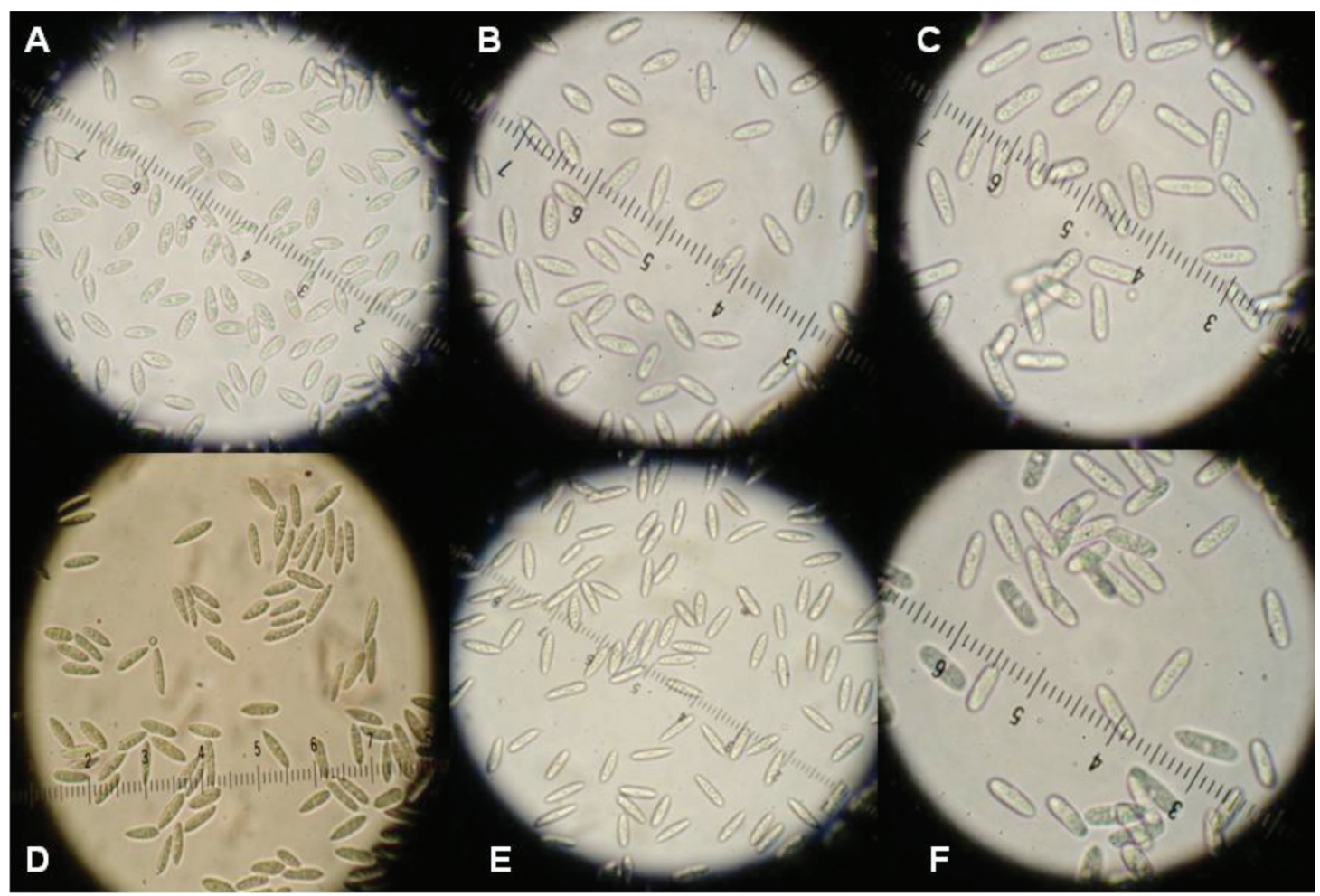

Fig. 7. Conidios de C. acutatum y C. gloeosporioides. (A, B) C. acutatum de carambola. (C) C. gloeosporioides de carambola. (D, E) C. acutatum de mango. (F) C. gloeosporioides de mango.

\section{DISCUSIÓN}

La morfología de las colonias y la sensibilidad a benomil son características útiles para la identificación de $C$. acutatum y $C$. gloeosporioides. En este estudio se determinó la presencia de estos patógenos en helecho hoja de cuero, limón criollo, papaya, carambola y mango mediante la prueba de sensibilidad a benomil y mediante la PCR con iniciadores específicos como prueba definitiva y certera para la determinación de la especie.

En el caso de limón criollo y helecho hoja de cuero se determinó a $C$. acutatum como agente causal de la antracnosis en estos hospederos, lo que corrobora los resultados obtenidos por Timmer en Florida (2000) y Schiller et ál. (2006) en Costa Rica (2006). La prueba de benomil resultó ser una prueba confiable en ambos casos, como lo demostraron estudios anteriores en cítricos (Peres et ál. 2004).

La mayoría de informes sobre antracnosis en cultivos tropicales señalan a $C$. gloeosporioides como agente causal de la enfermedad (Liyanage et ál. 1992, Mills et ál. 1992); sin embargo, existen informes sobre $C$. acutatum como causante de antracnosis en hospederos tropicales (Wharton y Diéguez 2004). En el presente estudio no se encontró evidencia de $C$. acutatum como causante de la antracnosis en papaya y mango en Costa Rica, mientras que en carambola se encontraron 3 aislamientos de C. acutatum. Al contrario, en Florida, para el caso de mango se aisló solamente a $C$. acutatum de los tejidos muestreados, lo que refuerza los datos presentados por Rivera et ál. (2006). De carambola de Florida se aisló 
únicamente $C$. gloeosporioides. Tanto en mango como en carambola y papaya, no hubo diferencias entre los síntomas causados por C. acutatum y los inducidos por C. gloeosporioides.

La prueba de benomil, aplicada como prueba única, no permitió la identificación de especies en la mayoría de los casos; el 96,5\% los aislamientos identificados molecularmente como C. acutatum resultaron positivos en la prueba de benomil; sin embargo, solo $78,3 \%$ de los aislamientos identificados como $C$. acutatum con la prueba de benomil fueron positivos en el análisis molecular.

El comportamiento de los aislamientos que presentaron igual crecimiento en medio con o sin benomil podría deberse a resistencia a este fungicida, pero se deben realizar más estudios para comprobarlo. La resistencia a benomil ha sido ampliamente documentada para $C$. gloeosporioides (Prior et ál. 1992, Barquero 2000) pero no para $C$. acutatum.

Asimismo, los 9 aislamientos de mango y los 14 de papaya identificados como C. acutatum mediante la prueba de benomil, y como C. gloeosporioides con la PCR, podrían ser aislamientos de $C$. gloeosporioides que no son totalmente resistentes al benomil, pero sí empiezan a mostrar resistencia parcial a este fungicida (Cuadro 2). Por consiguiente, se deben vigilar las aplicaciones de benzimidazoles en estos cultivos ya que se observó una tendencia a la resistencia y resistencia total de los aislamientos de C. gloeosporioides proveniente de estos cultivos.

Con respecto a la morfología de las colonias, ésta se debe establecer según el cultivo. En general, se definen las colonias de $C$. acutatum como colonias con una menor tasa de crecimiento (como lo demostraron las mediciones hechas en este estudio), de color blanco o naranja claro y algunas cromogénicas. Sin embargo, estas variables solamente se deberían analizar si existen muestras positivas de $C$. gloeosporioides o de $C$. acutatum en el hospedero que se analiza, para realizar una comparación objetiva.

La variabilidad en la morfología de las colonias provenientes de todos los cultivos analizados fue alta y en muchos casos el mismo aislamiento cambió su morfología al pasarlo a un medio de cultivo nuevo o al envejecer. Aislamientos de mango, carambola y papaya mostraron fenotipos distintivos de C. acutatum, pero los análisis demostraron que se trataba de $C$. gloeosporioides; asimismo aislamientos provenientes de helecho hoja de cuero identificados como C. acutatum, presentaron fenotipos similares a los de mango o papaya identificados como $C$. gloeosporioides.

La identificación por PCR de C. acutatum permitió posteriormente el análisis morfológico de estas colonias. Las colonias de C. acutatum provenientes de mango fueron blancas y con gran cantidad de acérvulos color naranja intenso (Figura 5G). Las colonias de C. acutatum de carambola fueron de color naranja claro, casi blanco, mucho más claras que las de C. gloeosporioides, y los conidios de aislamientos de ambos hospederos presentaron extremos puntiagudos.

En las colonias provenientes de helecho, algunas fueron claras, color naranja y algunas fueron grises, mientras que las provenientes de limón criollo fueron en su mayoría claras. Por lo tanto, no se debería asignar ninguna característica morfológica en general, o al menos no se debe identificar aislamientos de Colletotrichum sin tener un aislamiento con el cual comparar que provenga del mismo hospedero. Todas las herramientas deben utilizarse en conjunto para la adecuada identificación de especies ya que cada una de ellas por sí sola podría conducir a errores en la identificación o a un gasto innecesario de dinero, recursos humanos y tiempo.

El hallazgo de C. acutatum en carambola tiene importantes implicaciones epidemiológicas y es el primer informe de esta especie en carambola en Costa Rica. Aunque C. acutatum se encontró en menor frecuencia que causa antracnosis, un manejo inadecuado de las aplicaciones de fungicidas en este cultivo podría conducir a la selección de $C$. acutatum, que podría llevar a un equilibrio entre las poblaciones de ambas especies o incluso el dominio de la población de C. acutatum sobre C. gloeosporioides debido a la 
diferencia en sensibilidad a benomil entre ambas especies. Las mismas precauciones se deben de tener en cuenta al considerar el hallazgo de $C$. acutatum en mango en Florida.

Aunque en este estudio no se demuestra la presencia de $C$. gloeosporioides en mango en las regiones muestreadas en Florida, inconsistencias en el desarrollo de epidemias de antracnosis en mango en esta región sugieren que existe diversidad en las poblaciones del patógeno (Davis 1999).

Davis (1999) y Rivera et ál. (2006) identificaron a $C$. gloeosporioides y $C$. acutatum que causa antracnosis en mango en Florida. El primero identificó un grupo (basado en RAPD y pruebas de patogenicidad) proveniente de aislamientos de inflorescencias y frutos pequeños, menos virulento en hojas y frutos que otros aislamientos pero más virulento en inflorescencias. Los miembros de este grupo al igual que los aislamientos realizados en este estudio y los realizados por Rivera et ál. (2006), presentaron esporas punteadas en ambos extremos, lo que corresponde a C. acutatum. A diferencia de Davis (1999) y Rivera et ál. (2006), los aislamientos realizados en esta investigación provenían también de hojas, además de inflorescencias, y no se realizaron aislamientos de frutos inmaduros.

En comparación con el estudio realizado por Rivera et ál. (2006), la distribución de C.acutatum fue más amplia, ya que en su estudio solamente logró aislar 8 individuos procedentes de Homestead, mientras que en la actual investigación se aisló de Miami y Tampa únicamente C. acutatum. Ambos muestreos fueron realizados con 7 años de diferencia, lo que indicaría que la estructura y distribución de las poblaciones de Colletotrichum pudo haber variado con el tiempo ya que como se mencionó anteriormente, C. acutatum es mucho más resistente a benomil y azoxistrobina y el manejo de la enfermedad mediante estos productos pudo favorecer la proliferación de $C$. acutatum como fue predicho por Rivera et ál. 2006.

Los resultados obtenidos en investigaciones realizadas por otros autores indican que el análisis de las poblaciones mediante RAPDs podría arrojar resultados confusos, no es una metodología rigurosa debido a que individuos pertenecientes a una misma especie pueden ser divididos en grupos (Rivera et ál. 2006), con la identificación de especies por PCR con iniciadores específicos la mejor herramienta.

La diversidad de poblaciones en Florida ayuda a explicar por qué algunos cultivares de mango, resistentes a antracnosis, presentan susceptibilidad (Davis 1996) y además cobra importancia el hecho de determinar las especies presentes en cada zona antes de liberar variedades resistentes.

Finalmente, la humedad relativa y las temperaturas medias en los sitios muestreados en Florida son similares a las de las zonas en Costa Rica donde se produce mango, excepto por las variaciones a finales y principios de cada año, donde las 2 variables son menores en Florida. Estas similitudes en el clima, en conjunto con el comercio globalizado en la región y el manejo químico de la antracnosis en mango podrían conducir a cambios en las poblaciones de $\mathrm{C}$. $\mathrm{acu}$ tatum y $C$. gloeosporioides presentes en las diferentes zonas donde se da la producción de mango.

\section{LITERATURA CITADA}

ADASKAVEG J.E., HARTIN R.J. 1997. Characterization of Colletotrichum acutatum isolates causing anthracnose of almond and peach in California. Phytopathology 87:979-987.

AGOSTINI J.P., TIMMER L.W., MITCHELL D.J. 1992. Morphological and pathological characteristics of strains of Colletotrichum gloeosporioides from citrus. Phytopathology 82:1377-1382.

ARAUZ L.F. 2000. Mango anthracnose: Economic impact and current options for integrated management. Plant Disease 84:600-611.

ARCE E. 2003. Efecto de la caída prematura de los frutos de los cítricos causada por el hongo Colletotrichum acutatum en la producción de naranja en la Región Huetar Norte de Costa Rica. Tesis de maestría, Universidad de Costa Rica, San José, Costa Rica. $60 \mathrm{p}$.

BARQUERO C. 2000. Determinación de la sensibilidad a benomil en poblaciones de Colletotrichum gloeosporioides aislado de mango (Mangífera indica) en Costa Rica. Tesis de licenciatura, Universidad de Costa Rica, San José, Costa Rica. 32 p. 
BERNSTEIN B., ZEHR E.I., DEAN R.A., SHABI E. 1995. Characteristics of Colletotrichum from peach, apple, pecan, and other hosts. Plant Disease 79:478-482.

DAVIS M.J. 1999. Genetic and pathological diversity of the mango anthracnose pathogen in Florida. Proc. Fla. State Hort. Soc. 112:197-200.

FREEMAN S., MINZ D., MAYMON M., ZVEIBIL A. 2001. Genetic diversity within Colletotrichum acutatum sensu Simmonds. Phytopathology 91:586-592.

LARDNER R., JOHNSTON P.R., PLUMMER K.M., PEARSON M.N. 1999. Morphological and molecular analysis of Colletotrichum acutatum sensu lato. Mycological Research 103:275-285.

LIYANAGE H.D., McMILLAN R.T., KISTLER H.C. 1992. Two genetically distinct populations of Colletotrichum gloeosporioides from citrus. Phytopathology 82:1371-1376.

MILLS P.R., HODSON A., BROWN A.E. 1992. Molecular differentiation of Colletotrichum gloeosporioides isolates infecting tropical crops, pp. 250-269. In: J.A. Bailey and M.J. Jeger (eds.). Colletotrichum: Biology, Pathology and Control. Wallingford, UK. CAB International.

PERES N.A., SOUZA N.L., PEEVER T.L., TIMMER L.W. 2004. Benomyl sensitivity of isolates of Colletotrichum acutatum and C. gloeosporioides from citrus. Plant Disease 88:25-130.

PERES N.A., TIMMER L.W., ADASKAVEG J.E., CORRELL J.C. 2005. Lifestyles of Colletotrichum acutatum. Plant Disease 89:784-796.

RIVERA L., LUGO Y., McGOVERN R., SEIJO T., DAVIS M. 2006. Ocurrence and distribution of Colletotrichum spp., on mango (Mangifera indica L.) in Puerto Rico and Florida, USA. Plant Pathology Journal 5:191-198.

SCHILLER M., LŪBECK M., SUNDELIN T., CAMPOS L.F., DANIELSEN S., JENSEN D.F., MADRIZ K. 2006. Two subpopulations of Colletotrichum acutatum are responsible form anthracnose in strawberry and leatherleaf fern in Costa Rica European Journal of Plant Pathology 116:107-118.

SREENIVASAPRASAD S., SHARADA K., BROWN A.E., MILLS P.R. 1996. PCR based detection of Colletotrichum acutatum on strawberry. Plant Pathology 45:650-655.

SREENIVASAPRASAD S., TALHINHAS P. 2005. Genotypic and phenotypic diversity in Colletotrichum acutatum, a cosmopolitan pathogen causing anthracnose on a wide range of hosts. Molecular Plant Pathology 6:361-378.

TIMMER L.W., AGOSTINI J.P., ZITKO S.E., ZULFIQAR M. 1994. Postbloom fruit drop of citrus, an increasingly prevalent disease of citrus in the Americas. Plant Disease 78:329-334.

TIMMER L.W., BROWN G.E. 2000. Biology and control of anthracnose diseases of citrus, pp. 300-316. In: D. Prusky, S. Freeman and M.B. Dickman (eds.). Colletotrichum; Host Specificity, Pathology and Host- Pathogen Interactions. St.Paul, MN, US. APS Press.

UREÑA A.R., MITCHELL D.J., LEGARD D.E. 2001. Oversummer survival of inoculum for Colletotrichum crown rot in buried strawberry crown tissue. Plant Disease 85:750-754.

WHARTON P.S., DIÉGUEZ J. 2004. The biology of Colletotrichum acutatum. Anales del Jardín Botánico de Madrid 61:3-22.

WHITE T.J., BRUNS T., LEE S., TAYLOR J. 1990. Amplification and direct sequencing of fungal ribosomal RNA genes for phylogenetics, pp. 315322. In: M.A Innis, D.H. Gelfand, J.J. Sninsky and T.J. White (eds.). PCR Protocols: A Guide to Methods and Application. San Diego, CA, US. Academic Press.

XIAO C.L., MAcKENZIE S.J., LEGARD D.E. 2004. Genetic and pathogenic analysis of Colletotrichum gloeosporioides isolates from strawberry and noncultivated hosts. Phytopathology 94:446-453. 